\title{
The British Association of Perinatal Medicine: the first 25 years (1976-2000)
}

\section{P M Dunn}

The founding, achievements, and aspirations of the British Association of Perinatal Medicine are reviewed

\section{BACKGROUND}

Although there were pioneers in the 1930s and 1940s such as Dr Mary Crosse of Sorrento in Birmingham, newborn care in the United Kingdom was very neglected in the first half of the 20th century. ${ }^{1}$ In hospital, newborn babies were for the most part looked after by nursery nurses, midwives, and junior obstetricians. Two things changed this: the creation of the NHS in 1948 and the introduction of the umbilical exchange transfusion for Rh haemolytic disease, which established an entrée for paediatricians into maternity hospitals. But progress was slow and many errors in management were practiced. In the nurseries of a teaching maternity hospital in 1959 where I was neonatal registrar, there were no incubators, no technology, and no rooming in.

Why had newborn care been so neglected? Well, there were more babies than were needed and a fairly widespread attitude of "survival of the fittest". Obstetricians had become gynaecologists and many had lost their interest in the newborn. Paediatricians were few in number and were mostly based in children's hospitals; furthermore few had knowledge of the newborn.

The 1960s saw the establishment of special care baby units in major maternity units. But there was little equipment, and paediatric cover was poor. The perinatal mortality of 35 per 1000 births at the start of the decade fell only slowly. Progress, however, was being made in Scotland, and in England Peter Tizard had created a training ground for neonatologists at The Hammersmith Hospital. ${ }^{1}$ However, as there were no consultant posts in neonatal medicine, most of his trainees returned to general paediatrics. In 1968, I think I may have been the first person (certainly south of the border) to be appointed to a consultant perinatal/neonatal post.

In 1972, Donald Court, chairman of the BPA Academic Board, wrote a booklet with Tony Jackson entitled Paediatrics in the seventies. ${ }^{2}$ It contained the first official recognition of perinatal paediatrics as a specialty. Although stating that newborn care would remain the responsibility of general paediatricians, the authors recommended that a total of 10 perinatal paediatricians should be appointed to the various major centres throughout the country to supervise neonatal intensive care. This was to provide for an annual population of newborn infants in the United Kingdom of about 700000 , some $10 \%$ of which were anticipated to require special or intensive care.

In 1971 the Government published a report on special care for newborn babies. ${ }^{3}$ It contained the recommendation that there should be six special care costs per 1000 births, one of which should be for intensive care, with a total of eight nurses per 1000 deliveries per year to look after them. However, this totally inadequate nursing establishment was not actually available at that time or indeed for many years to come.

The state of paediatric staffing was no better. When I took up a consultant post at Southmead Hospital in the late 1960s, there were 6000 births a year and the referrals from at least another 6000 . The junior paediatric staffing to meet this case load consisted of half a registrar and two housemen. The annual budget for equipment at that time was $£ 500$. But we begged, borrowed, and stole and established an intensive care service in 1970. Everyone worked all hours, and in no time we were rewarded by a falling mortality. Between 1970 and 1973, the neonatal mortality for non-malformed infants over $1000 \mathrm{~g}$ birth weight fell by $74 \%$ in the university service. ${ }^{4}$ However, although such a fall may have been taking place in a few neonatal units around the country, it was not happening in general. ${ }^{4}$

Apart from the lack of finances generally available to the NHS, paediatrics had received a particularly raw deal, receiving possibly a third of the financing to which child health was entitled as its share of the medical budget ${ }^{5}$; and such money as was available was badly needed for older children. At the time, there were only 366 consultant paediatricians in the United Kingdom. Besides lacking an interest in the newborn, some paediatricians actively obstructed attempts to establish perinatal paediatrics. Maybe they saw their clinical workload being eroded by the development of paediatric specialisation and were loath to lose an interest in the newborn field, even though their commitment for this activity was inadequate.

So much for the background in the early 1970s. Half of all deaths from birth to 15 years were taking place in maternity hospitals within the first 3 days of life. ${ }^{4}$ For those of us trying on a shoestring to establish and maintain a neonatal intensive care service, it was most frustrating. In 1974 a leader in the Lancet, "The price of perinatal neglect", 6 drew attention to this. But no immediate action followed. Knowledge of what we should be doing for newborn infants was by now far ahead of what was actually provided. How best to proceed?

\section{FOUNDING OF THE BRITISH ASSOCIATION OF PERINATAL MEDICINE (BAPM) IN 1976}

In 1975 June Lloyd, who was then honorary secretary of the British Paediatric Association, asked me to find out for the Department of Health and Social Security the number of paediatricians in the United Kingdom working mainly in the newborn field. This I did by writing to all the major maternity hospitals and universities throughout Britain and Ireland, and enquiring whether there were any paediatricians spending $60 \%$ or more of their time in newborn care. Including eight from the Republic of Ireland, I collected 20 names in all. Then it occurred to me to bring these 20 paediatricians together and start a perinatal group. So I wrote to them early in 1976 asking them to meet at the BPA in York that April. At this point, Roy Meadow, who was then secretary to the BPA Academic Board, intervened. In York he put up a notice inviting anyone interested in newborn care to come to the meeting that I had arranged. After opening the meeting, he then left me to chair it. However, my intention had been to create a pressure group from among those actually facing the problems of providing a neonatal intensive care service. As this was now no longer possible, the meeting closed without making significant progress.

My next move was to invite those same 20 neonatal paediatricians to contribute to a neonatal symposium in Bristol in November 1976. This they agreed to do, and after the conference we formed the British Paediatric Perinatal Group (fig l) and celebrated the event with a dinner in the cellars of Foster's Rooms. Our declared aim was "to improve the standard of perinatal care in the British Isles". 


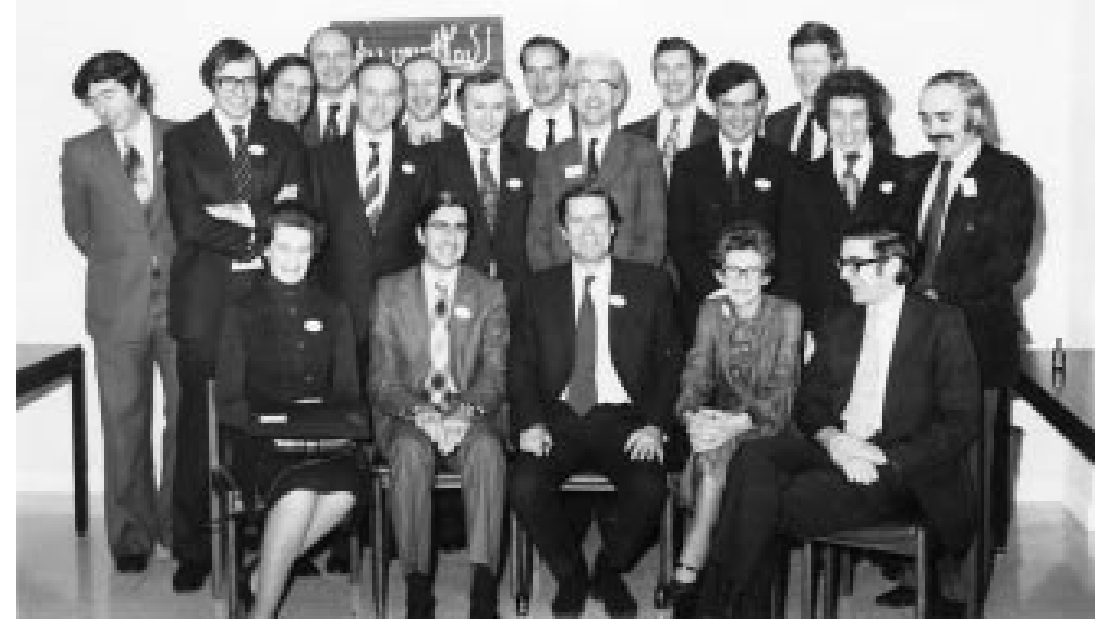

Figure 1 Founding meeting of the British Association of Perinatal Medicine, Bristol, 1976. Left to right: standing: Niall O'Brien, Roger Harris, David Davies, George Russell, Colin Walker, David Harvey, Brian Wharton, Forrester Cockburn, Cliff Roberton, John Maclaurin Richard Orme, Mark Reid, David Baum, Garth McClure; sitting: Pamela Davies, Osmund Reynolds, Peter Dunn, Margaret Kerr, Brian Speidel (in absentia: Malcolm Chiswick and Harold Gamsu).

My idea had been that there should also be a twin group, the British Obstetric Perinatal Group and that together we would create the British Association of Perinatal Medicine with combined meetings. I approached Richard Beard of St Mary's Hospital in London with this suggestion and the hope that he would organise the obstetric group. He was enthusiastic until senior colleagues at the Royal College of Obstetrics and Gynaecology (RCOG) dissuaded him. I then approached Charlie Whitfield of Glasgow. Exactly the same happened, as it did with my third approach to KnoxRitchie, then in Belfast. The official obstetric view at that time was that all gynaecologists were perinatologists, and that it was diversive to suggest that some were more perinatal than others. In addition, the RCOG, unlike the BPA, did not agree to our new group becoming affiliated with their College. This was disappointing as it seemed obvious that perinatal medicine could only be fully effective if the two disciplines most concerned worked closely together.

Meanwhile, I became secretary to the group and also honorary treasurer with the $£ 100$ I had raised from the Bristol Neonatal Symposium. All the founding members, along with later recruits,

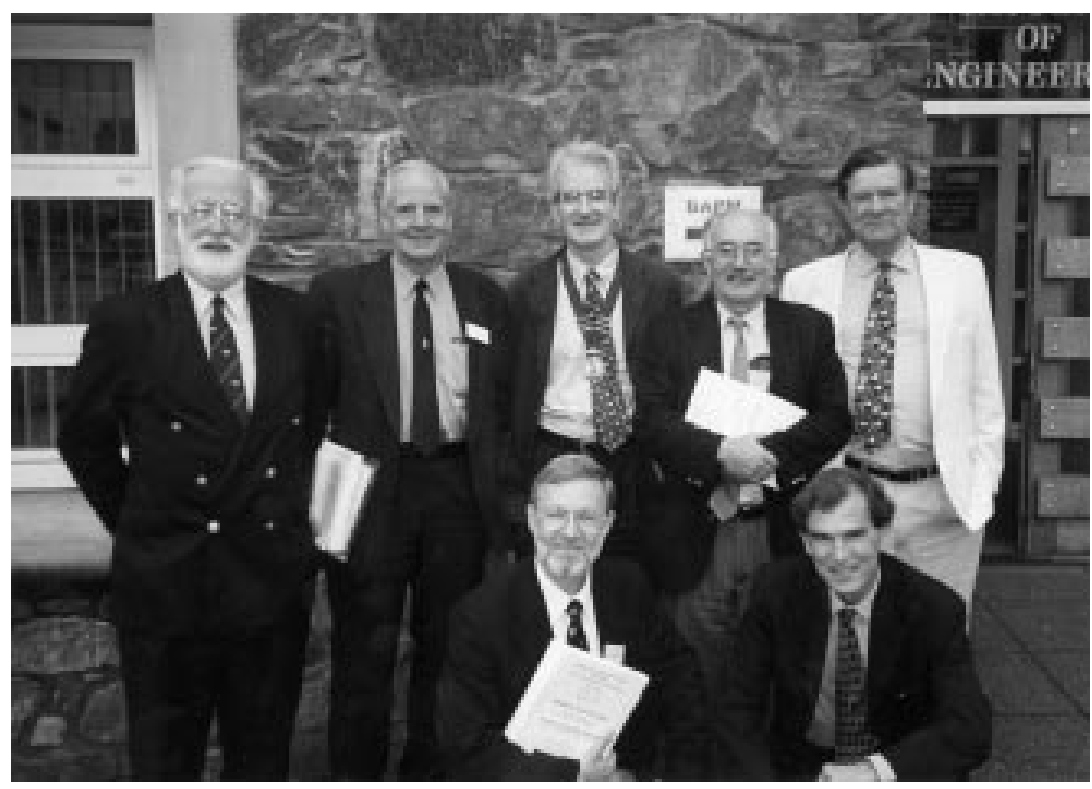

Figure 2 Presidents of the British Association of Perinatal Medicine (BAPM), 1976-2000. Standing, left to right: Clifford Roberton, Forrester Cockburn, Andrew Wilkinson, Garth McClure, Peter Dunn; kneeling: Philip Steer, Richard Cooke.

became members of our council, which met each year for a day's debate before our annual scientific meeting. These annual perinatal symposia, a continuation of the Bristol series, went peripatetic, visiting in turn most of the major cities throughout the British Isles and Ireland.

\section{PROGRESS IN PERINATAL CARE}

As the pace of work quickened, it was found necessary in 1980 to create an executive committee and the secretary became its chairman. For some time we used to meet in my home in Bristol. In 1982, Peter Tizard who gave our first founders' lecture, then pointed out that the correct term for a presiding officer was president, not chairman, and so we changed that title. We also changed our name from a perinatal group to British Association of Perinatal Paediatrics and registered ourselves as a charity.

In 1984, Cliff Roberton took over as president (fig 2). Cliff in turn was succeeded in 1987 by Forrester Cockburn. Then followed Richard Cooke in 1990 and Garth McClure in 1993. Next, in 1996 Phil Steer became our first "obstetric" president. From the start we had welcomed obstetricians to join our paediatric group and, in fact, in 1980 Phil had become a valued member of our executive committee. In 1982 the RCOG recognised maternal and fetal medicine as a subspecialty of obstetrics and gynaecology. The chairman of the RCOG working party that made that recommendation was Charlie Whitfield, and indeed it was he who, in 1985, suggested that the time had come to rename our association the British Association of Perinatal Medicine. This we did in 1987 and at the same time acquired a logo, designed by a young lad from Ulster. So at last perinatal medicine had been established in this country with its own representative association.

In fact many disciplines contribute to perinatal care, and from the early days we have had at our meetings members and representatives from pathology, anaesthetics, midwifery, radiology, paediatric surgery, family and community practice, epidemiology, neonatal nursing, and administration-the Department of Health. In particular, we invited from 1978 onwards two neonatal nurses, the late Jean Boxall of Exeter and Paula Hale of Nottingham, to become members of our council. It was they too who together helped to create that same year the Neonatal Nurses Association with a constitution very similar to our own. Both of these splendid nurses were later made honorary members of our association.

The BAPM has many activities and functions: as a pressure group to improve perinatal care; to audit facilities and workload; to define standards for staffing, cots, and equipment; to train staff; to 
undertake postgraduate education; to act as a scientific forum; to organise multicentre trials; and to promote collaboration and good fellowship. Although many of the BAPM's achievements are listed in its handbook, ${ }^{7}$ it is worth mentioning one in particular. This was obtaining formal recognition for perinatal paediatrics with its own training programme from the Royal Colleges and BPA. It proved difficult because of the many professional bodies involved and the prejudice of some senior colleagues; indeed it took years of negotiation. In 1977 I started with an approach to the BPA Academic Board. Ross Mitchell was then the chairman of the board and was more sympathetic to our cause than most. However, the correspondence that I had with him in 1977 makes interesting reading 23 years later. In short, he stated that neonatology was likely to remain largely in the hands of general paediatricians and that therefore the board would not press for perinatal or neonatal paediatrics to be recognised as a paediatric subspecialty for the purposes of accreditation. In fact, the breakthrough took six years to achieve. Our cause was helped by the publication of Donald Court's child health report Fit for the future, ${ }^{8}$ which labelled the unnecessarily high perinatal mortality as a holocaust, and then in 1980 by the massive five volume "Short report" " $^{\text {"9 }}$ of the House of Commons Social Services Committee, which emphasised the gross neglect of perinatal medicine in this country, and urged the recognition of the specialty and the immediate appointment of 50 consultant neonatologists. Officially there were still only 12 in the United Kingdom at that time. ' Many gave evidence to that committee and in particular the BPA/RCOG Liaison Committee prepared a discussion document entitled "Recommendations for the improvement of infant care during the perinatal period", 5 which had a major impact. But special credit must go to Osmund Reynolds who represented neonatology on Reneé Short's committee.

Another most important advance was the Körner report in $1982 .{ }^{10}$ It gave me particular satisfaction by recommending that every newborn infant should in future be identified as a patient from birth and that there should be a minimum data set for the baby as well as for the mother. At last, the $90 \%$ so called "normal" newborn babies not receiving special or intensive care emerged from what John Ballantyne ${ }^{1}$ described in 1916 as the "no-man's land" between obstetrics and paediatrics.

Tremendous progress has been made in newborn care during the last 25 years. Smaller and smaller infants have survived with the help of intensive care, and the perinatal mortality has fallen to a quarter of what it was in 1976. The BAPM made its contribution thanks to the efforts of many, especially the honorary secretaries. Harold Gamsu took over from me in 1980, followed by David Harvey (1983), Malcolm Chiswick (1986), Malcolm Levene (1989), Andrew Wilkinson (now our president) (1992), Neil Marlow (1995), and, at present, Janet Rennie (1998). Mention should also be made of our honorary treasurer, David Lloyd, who took over the management of our financial affairs from me in 1988 and has done a magnificent job. The fourth officer, the honorary archivist, is planning to retire later this year and to hand his baton on to David Harvey. Nor should we overlook the splendid achievements of our Multi-centre Trials Group led since 1991 by Henry Halliday and more recently by Steve Walkinshaw. This group has worked closely with Iain Chalmers, previously of the National Perinatal Epidemiology Unit in Oxford. Some 17 multicentre trials are in progress.

Since the first annual founders' lecture by Sir Peter Tizard in 1982, we have listened to many distinguished speakers, some 20 in all. All have become honorary members. There are now 45 such members; but, alas, eight are no longer with us: Peter Tizard, Alec Turnbull, Jean Boxall, Kenneth Cross, Geoffrey Dawes, Leonard Strang, Jon Scopes, and David Baum. David, a founder member, became President of the Royal College of Paediatrics and Child Health (RCPCH) in 1997. He was an inspiration in so many ways and his death is a great loss to paediatrics as well as to perinatal medicine and to all of us personally. Some years ago he wrote: "Perinatal medicine is the biggest most rapidly growing and effective specialty in paediatrics".

We have come a long way since our Perinatal Group first met at the Bristol Maternity Hospital (now St Michael's Hospital) just half a mile away. We now have some 550 members including 62 professors. Eight of the original 20 founder members are here today and most of the remainder have sent their apologies and their good wishes. As I will be retiring shortly, I hope you will permit me to tell you of some of my hopes for our Association in the years to come.

\section{THOUGHTS ON THE FUTURE}

One of my keenest concerns is that we all-obsetricians, midwives, paediatricians, and neonatal nurses-continue to work closely as a team. ${ }^{11}$ I believe we are only likely to achieve this if we understand and share each other's problems. Joint clinics and ward rounds help. Even better though would be the inclusion of some obstetrics in the training of perinatal paediatricians and vice versa, as was originally proposed 20 years ago. Alas, the truncated Calman training programme and the current pressure of work has threatened to undermine this important strategy.

Another way of focusing on and improving the perinatal training of obstetricians and paediatricians may be to prepare a syllabus of knowledge basic to the care of the fetus and newborn and award a diploma to those reaching an appropriate standard. I very much hope that this will indeed be achieved within the coming decade under the general auspices of the two parent Royal Colleges.

The importance of perinatal audit is self evident, and the BAPM has already made considerable progress in this area. If we professionals fail to take a lead in this matter, others such as administrators and politicians may pre-empt us with systems less likely to meet our needs. It is important too that our audit should include all babies, and not just those requiring special and intensive care.

The BAPM has always been a pressure group, and its political clout has been steadily increasing. However, there remains some confusion stemming from the fact that our discipline lies halfway between the two Royal Colleges. Hopefully, the day will arrive when we become formally affiliated with the RCOG as we are already with the RCPCH and when our executive committee then becomes the source of advice on perinatal matters to both Colleges. This will I am sure come about in due course, but is likely to be hastened if we increase our membership, especially of obstetricians, and if we have our own independent base. As long as the BAPM administrative office is housed in the College of Paediatrics, as it is at present, we will be seen by obstetricians as a mainly paediatric organisation. So a major initiative in fund raising is required with a view to purchasing or renting our own accommodation.

We have moved into bewildering times of high technology, ${ }^{11}$ but we must be very careful not to allow our clinical skills to atrophy as a result. The art of medicine must not be submerged by science. Each individual patient is unique and does not necessarily obey the dictates of a metaanalysis. Also we must never lose sight of those two cardinal precepts in medicine: "Prevention is better than cure", and "First of all, do no harm". Parturition is a particularly fertile ground for iatrogenesis. For example, there is the rising prevalence of iatrogenic multiple pregnancy, the many routine interventions during labour, and the ever rising caesarean section rate. We must, I believe, get back to first principles and study the wonderful physiology of childbirth and fetal adaptation to extrauterine life, and do everything possible to avoid interference with normal mechanisms.

Once the baby is delivered, we must seize the opportunity to screen both 
mother and baby for medical pathology, for socioeconomic problems, for psychological stress, and for ignorance on parenting. ${ }^{12}$ Birth provides the most wonderful opportunity for screening a population and getting families off to the best possible start. Every baby has the right to a skilled examination on the first day of life, ${ }^{13}$ and every mother has the right to know at once the results of such an examination. As a discipline, it is essential that paediatricians do not withdraw into their intensive care units. Equal attention and care should be given to all babies, wherever they are born and however normal they may appear to be.

And if I may have one last wish it is that we will, in future, take more advantage of the school years to educate children on how best to live healthy lives, how to prepare for pregnancy and childbirth, and how to bring up their own families when the time comes. There are so many important lessons to be learnt, the most important of which are to avoid smoking, drugs, and promiscuous sex, and the great advantages of breast feeding. And in this task we need to enlist the help of the teachers and give them the necessary information to pass on to children from a young age.
It is time for me to end. Perinatal medicine is, I believe, the best of all the medical disciplines. Of course it is stressful and of course there are problems at times, but there are also tremendous rewards, and we should consider ourselves very privileged to call ourselves perinatal physicians.

Arch Dis Child 2003;88: 181-184

\section{Authors' affiliations}

P M Dunn, Emeritus Professor of Perinatal Medicine and Child Health, University of Bristol, Southmead Hospital, Bristol BS10 5NB, UK

This paper was read at the BAPM 25th Jubilee Scientific Meeting, Bristol, 8-9 September 2000.

Correspondence to: Professor Dunn, Department of Perinatal Medicine and Child Health, University of Bristol, Southmead Hospital, Bristol BS10 7AD, UK; p.m.dunn@bristol.ac.uk

\section{REFERENCES}

1 Dunn PM. The development of newborn care in the UK since 1930. American Academy of Pediatrics Thomas E. Cone Jr Lecture on Perinatal History. J Perinat 1998;18:471-6.

2 Court D, Jackson A (eds). Paediatrics in the seventies. Developing the child health services. London: Oxford University Press, 1972:45.

3 Expert Group on Special Care for Babies. Reports on Public Health Medical Subjects no 127. London: HMSO, 1971.
4 Dunn PM. Perinatal statistics. In: House of Commons Social Services Committee Session, 1979-1980. Second report: perinatal and neonatal mortality. London: HMSO, 1980:2:256-67.

5 British Perinatal Association/Royal College of Obstetrics and Gynaecology Liaison Committee. Recommendations for the improvement of infant care during the perinatal period. Discussion document. London: British Paediatric Association and Royal College of Obstetricians and Gynaecologists, 1978.

6 The price of perinatal neglect [editorial] Lancet 1974;1:437.

7 Dunn PM. The history of the British Association of Perinatal Medicine, 1976-1999. In: British Association of Perinatal Medicine handbook, 2000-2001. London, BAPM, 2000:9-11.

8 Committee on Child Health Services. Fit for the future. London: HMSO, 1976. (Cmnd 6684 , vols I and III..

9 House of Commons Social Services Committee Session 1979-80. Second report: perinatal and neonatal mortality. London: HMSO, 1980.

10 National Health Service/Department of Health and Social Security Steering Group on Health Service Information. First report of the Secretary of State, 1982. London: HMSO: 1-41.

11 Dunn PM. Perinatal reflections. Prenatal and Neonatal Medicine 1998:3:367-70.

12 Dunn PM. Examination of the newborn infant in the UK: a personal viewpoint. Journal of Neonatal Nursing 2002;7:55-7.

13 International Federation of Gynecologists and Obstetricians (FIGO) Committee for the Ethical Aspects of Human

Reproduction and Women's Health. Ethical aspects of newborn care. London: FIGO, 2000:43.

Recent Advances in Paediatrics 20

Edited by Tim J David. £35.00 ISBN: 1-85315-509-8

Recently updated, this book covers a variety of specialties including general paediatrics, neonatal, tropical, and community paediatrics.

For further details or to order a copy please contact the

Royal Society of Medicine Press Ltd,

Marston Book Services, PO Box 269, Abingdon, Oxfordshire OX14 4YN, UK

Tel: $+44(0) 1235465500$

Fax: +44 (0) 1235465555

Email: sarah.matthews@rsm.ac.uk

Web site: http://www.rsmpress.co.uk 